\title{
Light alters the impacts of nitrogen and foliar pathogens on the performance of early successional tree seedlings
}

\author{
Alexander Brown ${ }^{1,2}$, Robert W Heckman ${ }^{\text {Corresp. 1,3 }}$ \\ 1 Department of Biology, University of North Carolina at Chapel Hill, Chapel Hill, North Carolina, United States \\ 2 Curriculum for the Environment and Ecology, University of North Carolina at Chapel Hill, Chapel Hill, North Carolina, United States \\ 3 Department of Integrative Biology, University of Texas at Austin, Austin, Texas, United States \\ Corresponding Author: Robert W Heckman \\ Email address: robert.heckman@utexas.edu
}

Light limitation is a major driver of succession and an important determinant of the performance of shade-intolerant tree seedlings. Shade intolerance may result from a resource allocation strategy characterized by rapid growth and high metabolic costs, which may make shade-intolerant species particularly sensitive to nutrient limitation and pathogen pressure. In this study, we evaluated the degree to which nitrogen availability and fungal pathogen pressure interact to influence plant performance across different light environments. To test this, we manipulated nitrogen availability (high, low) and access by foliar fungal pathogens (sprayed with fungicide, unsprayed) to seedlings of the shadeintolerant tree, Liquidambar styraciflua, growing at low and high light availability, from forest understory to adjacent old field. Foliar fungal damage varied with light and nitrogen availability; in low light, increasing nitrogen availability tripled foliar damage, suggesting that increased nutrient availability in low light makes plants more susceptible to disease. Despite higher foliar damage under low light, spraying fungicide to exclude pathogens promoted $14 \%$ greater plant height only under high light conditions. Thus, although nitrogen availability and pathogen pressure each influenced aspects of plant performance, these effects were context dependent and overwhelmed by light limitation. This suggests that failure of shade-intolerant species to invade closed-canopy forest can be explained by light limitation alone. 
Title: Light alters the impacts of nitrogen and foliar pathogens on the performance of early successional tree seedlings

Authors: Alexander N. Brown ${ }^{1,2}$, Robert W. Heckman ${ }^{1,3}$

Affiliations: ${ }^{1}$ Department of Biology, University of North Carolina Chapel Hill, Chapel Hill, NC 27599; ${ }^{2}$ Curriculum for the Environment and Ecology, University of North Carolina Chapel Hill, Chapel Hill, NC 27599; ${ }^{3}$ Present address: Department of Integrative Biology, University of Texas at Austin, Austin, TX 78712

Correspondence: robert.heckman@utexas.edu

Keywords: American sweetgum; foliar fungal pathogens; old field succession; Pseudocercospora liquidambaricola; shade tolerance; top-down, bottom-up

Author contributions: ANB and RWH designed and performed the experiment, analyzed the data, and wrote the manuscript. 


\section{Abstract}

2 Light limitation is a major driver of succession and an important determinant of the

3 performance of shade-intolerant tree seedlings. Shade intolerance may result from a resource

4 allocation strategy characterized by rapid growth and high metabolic costs, which may make

5 shade-intolerant species particularly sensitive to nutrient limitation and pathogen pressure. In this

6 study, we evaluated the degree to which nitrogen availability and fungal pathogen pressure

7 interact to influence plant performance across different light environments. To test this, we

8 manipulated nitrogen availability (high, low) and access by foliar fungal pathogens (sprayed with

9 fungicide, unsprayed) to seedlings of the shade-intolerant tree, Liquidambar styraciflua, growing

10 at low and high light availability, from forest understory to adjacent old field. Foliar fungal

11 damage varied with light and nitrogen availability; in low light, increasing nitrogen availability

12 tripled foliar damage, suggesting that increased nutrient availability in low light makes plants

13 more susceptible to disease. Despite higher foliar damage under low light, spraying fungicide to

14 exclude pathogens promoted 14\% greater plant height only under high light conditions. Thus,

15 although nitrogen availability and pathogen pressure each influenced aspects of plant

16 performance, these effects were context dependent and overwhelmed by light limitation. This

17 suggests that failure of shade-intolerant species to invade closed-canopy forest can be explained

18 by light limitation alone.

\section{INTRODUCTION}

21 Shade-intolerant species are, by definition, unable to persist in low-light environments.

22 This may occur because shade-intolerant species tend to allocate resources toward rapid growth

23 and limited defense (Walters and Reich 1999, Myers and Kitajima 2007, Valladares and 
24 Niinemets 2008). Because this shade-intolerant strategy prioritizes growth of new tissue over

25 defense against consumers, the performance and survival of shade-intolerant plants may decline

26 in environments where growth is slowed by nutrient or light limitation. Importantly, in these

27 resource-limited environments, performance and survival can be further reduced by high

28 consumer pressure (Coley et al. 1985, Fine et al. 2004, Hahn and Maron 2016). In this way,

29 consumer pressure may interact with light and nutrient availability to drive succession from

30 high-light, early-successional fields to low-light, later-successional forests (Augspurger 1984b,

31 Coley et al. 1985, Myers and Kitajima 2007, Pasquini et al. 2015, Griffin et al. 2016).

32 The impacts of consumers on shade-intolerant species may increase as light and nutrients

33 decline. This is because the fast-growing, poorly defended strategy is only advantageous when

34 resources are ample enough to support high growth rates. Otherwise, these plants cannot

35 maintain their high metabolic rates. By consuming plant tissue, pathogens and herbivores further

36 reduce the ability of these plants to acquire the resources (e.g., light, nutrients, water) necessary

37 for the growth and maintenance of their metabolically costly tissue, potentially driving

38 precipitous declines in performance. Thus, in low-light conditions, shade-intolerant species may

39 be especially susceptible to disease for several reasons. First, shade-intolerant species often

40 exhibit low constitutive defenses (Stamp 2003). Second, limitation by nutrients and light may

41 prevent plants from constructing some defense compounds (Hanssen et al. 2020, Huang et al.

42 2020). Third, light limitation may lead to the down-regulation of both the salicylic and jasmonic

43 acid pathways (de Wit et al. 2013), which are key to responding to attack by pathogens and

44 herbivores (Thaler et al. 2012, de Wit et al. 2013, Ballaré and Pierik 2017). Moreover, nutrient

45 limitation may be especially detrimental for shade-intolerant species (e.g., Ward 2020), because

46 it can drastically reduce their ability to build photosynthetic machinery and some defensive 
47 compounds (Coley et al. 1985, Stamp 2003, Hanssen et al. 2020). Thus, susceptibility to

48 pathogens among shade-intolerant species may be particularly high when light and nutrients are

49 limiting (Kitajima and Poorter 2010, Griffin et al. 2016, Griffin et al. 2017).

50 Regardless of resource availability, pathogens are critical drivers of dynamics in plant

51 communities (Mordecai 2011). Throughout forest and grassland systems, pathogens can limit

52 seedling survival (Hersh et al. 2012), ecosystem productivity (Mitchell 2003, Maron et al. 2011),

53 species' ranges (Spear et al. 2015, Bruns et al. 2019), and can promote diversity (Bever et al.

54 2015, LaManna et al. 2017). Pathogens can alter community composition through negative

55 density-dependent seedling mortality (Comita et al. 2014, Bayandala et al. 2017, Uricchio et al.

56 2019, Jia et al. 2020), benefiting more resistant species (Welsh et al. 2016, Cappelli et al. 2020),

57 and those that have escaped their specialist herbivores and pathogens (Heckman et al. 2016,

58 Heckman et al. 2017). Because pathogen impacts can also change with light and nutrient

59 availability (e.g., Dordas 2009, Veresoglou et al. 2013, Heckman et al. 2016, Ballaré and Pierik

60 2017, Liu et al. 2017, Agrawal 2020), shade-intolerant species may experience large differences

61 in pathogen impacts across the range of habitats they occupy (Augspurger 1984a). Thus,

62 pathogens may reinforce shade-tolerance differences among species, promoting niche

63 differentiation (McCarthy-Neumann and Kobe 2008, Krishnadas and Comita 2018).

64 In this study, we assessed the role of light and nitrogen supply in seedling susceptibility

65 to pathogens and how pathogen impacts on seedling performance are mediated by light and

66 nitrogen. We did this using an important pioneer species of old fields and early-successional

67 forests, Liquidambar styraciflua (Oosting 1942, Wright and Fridley 2010, Fridley and Wright

68 2018). In these early-successional environments, L. styraciflua can experience severe foliar

69 disease (McElrone et al. 2010) and varied nutrient and light conditions. Thus, the interaction 
70 between pathogens and resource supply may be important for understanding successional

71 dynamics. To date, this interaction has been addressed in only a few studies in natural systems

72 (e.g., Griffin et al. 2016, Griffin et al. 2017, Ward 2020). We predicted that:

73 1) Foliar fungal pathogen damage will be highest when light and nitrogen are both limiting.

74 2) Pathogen impacts on seedling height, a proxy for plant performance, will be highest when $75 \quad$ light and nitrogen are both limiting.

76

77 MeTHODS

78 Study system

Liquidambar styraciflua is a shade-intolerant deciduous tree that is common throughout

80 the southeastern US. L. styraciflua is a key transitional species during succession-it competes

81 well in early successional systems, but becomes less common as seedlings become increasingly

82 shaded during succession (Clark et al. 2004, Wright and Fridley 2010, Hersh et al. 2012,

83 Addington et al. 2015, Brown et al. 2020).

84 Seedling propagation

85 We purchased L. styraciflua seeds from Sheffield's Seed Co. (Locke, NY). In the 86 greenhouse at the University of North Carolina at Chapel Hill, we sowed seeds into flats. Ten 87 days after germinating, each seedling was transplanted into a $2.84 \mathrm{~L}$ pot filled with 3:1 mix of 88 potting mix (Fafard 3B; Sun Gro) and sterilized sand. To ensure that other soil nutrients would 89 not limit seedling growth, the potting medium included $10 \mathrm{~g} \mathrm{P} \mathrm{m}^{-2}$ as triple super phosphate, $10 \mathrm{~g}$ $90 \mathrm{~K} \mathrm{~m}^{-2}$ as potassium sulfate, and $100 \mathrm{~g} \mathrm{~m}^{-2}$ micronutrients (Scotts Micromax, Marysville, $\mathrm{OH}$ ), 91 corresponding to $1 \mathrm{~g}$ triple super phosphate plant ${ }^{-1}, 0.45 \mathrm{~g}_{\text {potash }}$ plant ${ }^{-1}$, and $2 \mathrm{~g}$ micronutrients 92 plant $^{-1}$ (Borer et al. 2014). On July 17, 2014, seedlings were moved to the field. 
93

94

9

97

100

101

102

103

104

105

106

107

108

109

110

112

113

114 115

Site description

We performed this experiment in an old field and adjacent forest in the Duke Forest Teaching and Research Laboratory, (Orange Co., NC). The old field has been maintained since 1996 through annual mowing. In the old field, L. styraciflua occurs as seedlings and small saplings. The adjacent forest is $\sim 40$ years old and dominated by early successional trees such as Pinus taeda, Liriodendron tulipifera and L. styraciflua. Later successional species like Acer rubrum and Quercus spp. also occur throughout the forest.

We conducted this field experiment between July 17 and October 3, 2014 (11 weeks) using a split-plot design. At the whole plot level, we manipulated light availability; at the subplot level, we manipulated nitrogen availability and foliar fungal pressure. Each subplot was a single sweetgum seedling grown in its own pot; each whole plot was a cluster of four pots surrounded with a wire cage to exclude deer.

\section{Light availability}

At the whole plot level, we assigned seedlings to levels of light availability using a replicated regression approach (Cottingham et al. 2005). This entailed high replication (10×) at the two extremes — closed canopy (low light) and open field (high light) — and lower replication $(4 \times)$ at three points along a transect from low to high light — at the forest edge, $\sim 5 \mathrm{~m}$ from the forest edge, and $\sim 10 \mathrm{~m}$ from the forest edge. Replicates were spaced $\sim 5 \mathrm{~m}$ apart.

To assess light differences among treatments, we used Onset HOBO pendant light loggers (Onset Computer Corporation, Bourne, MA). Loggers recorded light availability every 5 minutes for 10 days in early October. Because overstory trees had not yet begun to noticeably senesce and no disturbances (e.g., tree falls) had occurred, light availability in October should reflect relative light availability throughout the experiment. 


\section{Nitrogen supply}

117 Seedlings received five applications of aqueous ammonium nitrate $\left(\mathrm{NH}_{4}{ }^{+} \mathrm{NO}_{3}{ }^{-}\right)$over ten

118 weeks (July 24 - September 18). Seedlings under high nitrogen received $2 \mathrm{~g} \mathrm{~N} \mathrm{~m}^{-2}$ application $^{-1}$

119 (in total, $10 \mathrm{~g} \mathrm{~N} \mathrm{~m}^{-2}$ or $460 \mathrm{mg} \mathrm{NH}_{4}{ }^{+} \mathrm{NO}_{3}-$ plant ${ }^{-1}$ ); seedlings under low nitrogen received $0.2 \mathrm{~g} \mathrm{~N}$

$120 \mathrm{~m}^{-2}$ application ${ }^{-1}$ (in total, $1 \mathrm{~g} \mathrm{~N} \mathrm{~m}^{-2}$ or $46 \mathrm{mg} \mathrm{NH}_{4}{ }^{+} \mathrm{NO}_{3}{ }^{-}$plant ${ }^{-1}$ ). In previous studies, the high

121 nitrogen application rate increased soil nitrogen (Stevens et al. 2015) and alleviated nitrogen

122 limitation at this site (Fay et al. 2015).

\section{Fungal pathogen pressure}

124 Seedlings were either sprayed biweekly with a foliar fungicide or left unsprayed. This

125 fungicide, Mancozeb (Dithane DF, Dow AgroSciences, Indianapolis, IN), was applied in late

126 morning until it began to run off leaves. Mancozeb is a broad-spectrum non-systemic fungicide

127 that has no known direct effects on photosynthesis, leaf longevity, shoot growth, or root growth

128 (Lorenz and Cothren 1989, Kope and Trotter 1998, Parker and Gilbert 2007), nor does it affect

129 mycorrhizal fungi when applied at recommended rates (Parker and Gilbert 2007). In a separate

130 greenhouse study, fungicide reduced total biomass by $\sim 10 \%$, but this effect was only marginally

131 significant $(\mathrm{P}=0.084$; Table S1a; Fig. S1a, Supplementary Methods 1).

132 In total, this experiment comprised 32 whole plots (10 high light, 10 low light, 4 at each

133 of 3 points along a light transect; Fig. S3). Within each whole plot, there were 4 seedlings (2

134 nitrogen $\times 2$ fungicide treatments), each growing in a separate pot, for a total of 128 seedlings.

\section{Measurements}

136 In this study, we measured two responses — foliar damage and plant height — to determine

137 whether light and nitrogen availability alter pathogen impacts on seedlings. Foliar pathogen

138 damage was quantified visually by referring to digitized images of known damage severity 
139 (James 1971, Mitchell et al. 2002, Mitchell et al. 2003). We measured foliar damage as the

140 percent of leaf area visibly damaged on October 3, 2014 (after 11 weeks in the field) on up to

141 five leaves per plant, including the youngest and oldest leaves as well as three leaves evenly

142 spaced in age. We measured damage as $0 \%, 0.1 \%, 0.5 \%$, by $1 \%$ increments between 1 and $15 \%$

143 damage, then by 5\% increments above this. Surveying leaves of different ages should best

144 describe the mean level of damage across the entire plant, because damage typically increases

145 with leaf age (Hatcher et al. 1995, Halliday et al. 2017, Heckman et al. 2019). Plant height was

146 measured biweekly from July 25 until October 3, 2014 (6 observations over 73 days). Each time,

147 we measured seedling height from the base through the end of the petiole of the highest leaf,

148 which reflects the highest point at which seedlings can photosynthesize.

149 Data Analysis

150 We analyzed these data with linear mixed models in the nlme package (Pinheiro et al.

151 2016) in R version 3.5.3 (R Foundation for Statistical Computing, Vienna 2019). In all models,

152 light was a categorical whole plot effect. Because both maximal and total daily light availability

153 were similar for transect and high light seedlings $(\mathrm{P}=0.18$; Fig. $\mathrm{S} 2)$, we combined these light

154 treatments for all analyses. Thus, 88 seedlings from 22 whole plots were treated as high light and

15540 seedlings from 10 whole plots were treated as low light. Nitrogen and spraying treatments

156 were categorical subplot effects.

157 We quantified seedling height as the area under the curve of biweekly height

158 measurements using the 'auc' function in the MESS package (Ekstrøm 2016). To meet the

159 normality assumption for linear models, foliar fungal damage was cubed-root transformed. This

160 transformation best met the normality assumption because it is more strongly normalizing than

161 the square root transformation, but less so than the log transformation. To reduce 
162 heteroscedasticity of height residuals, we used the varIdent function in 'Ime' to allow variances

163 to differ between light treatments (Zuur et al. 2009, Pinheiro et al. 2016). Post-hoc Tukey HSD

164 tests were performed using the 'emmeans' function (Lenth 2018).

165

166 RESULTS

167 Impacts of light and nitrogen on fungicide efficacy

168

Averaged across all light and nitrogen treatments, fungicide reduced fungal damage by

$16983 \%$ (Spraying, $\mathrm{P}<0.001$; Fig. 1a). Light and nitrogen availability jointly altered the effect of

170 fungicide on visible foliar fungal damage (Light $\times$ Nitrogen $\times$ Fungicide; $\mathrm{P}=0.03$; Table S2): in

171 high light, spraying did not alter fungal damage in either nitrogen level (Tukey HSD: High

172 nitrogen, $\mathrm{P}=0.99$; Low nitrogen, $\mathrm{P}=0.83$ ); in low light, spraying reduced fungal damage to

173 near zero at both nitrogen levels (Tukey HSD: High nitrogen, $\mathrm{P}<0.001$; Low nitrogen, $\mathrm{P}=$

$1740.001)$.

175 Impacts of light and nitrogen on foliar fungal damage

176 Among unsprayed seedlings, there were no significant main effects of nitrogen or light on

177 foliar fungal damage (Nitrogen: $\mathrm{P}=0.5$; Light, $\mathrm{P}=0.11$; Table $\mathrm{S} 3$ ). Instead, light availability

178 altered the effect of nitrogen on foliar fungal damage (Nitrogen $\times$ Light, $\mathrm{P}=0.01$; Table S3; Fig.

179 1b): in high light, fungal damage did not differ between nitrogen treatments (Tukey HSD: $\mathrm{P}=$

180 0.078); in low light, fungal damage was over $3 \times$ higher on high nitrogen than low nitrogen

181 seedlings (Tukey HSD: $\mathrm{P}=0.039$ ). This is contrary to our prediction that damage would be

182 highest under low light and low nitrogen.

183 Impacts of light, nitrogen, and fungicide on seedling height

184 Although light and nitrogen each had significant main effects on seeding height (Light, P 
$185<0.001$; Nitrogen, $\mathrm{P}=0.022$; Table S4), these two factors interacted to influence seedling height

186 (Nitrogen $\times$ Light, $\mathrm{P}=0.004$; Table S4). In high light, seedlings grew $17 \%$ taller in the high

187 nitrogen treatment than the low nitrogen treatment (Tukey HSD: $\mathrm{P}<0.001$ ). Height did not

188 differ among nitrogen treatments in low light (Tukey HSD: $\mathrm{P}=0.62$ ).

189 Fungicide did not have a significant main effect on seedling height $(\mathrm{P}=0.14)$. Instead,

190 light availability altered the effect of fungicide on seedling height (Fungicide $\times$ Light, $\mathrm{P}=0.002$;

191 Table S4; Fig. 2): in high light, sprayed seedlings grew 14\% taller than unsprayed seedlings, but

192 did not differ in low light (Tukey HSD: High light, $\mathrm{P}=0.002$; Low light, $\mathrm{P}=0.22$ ). Thus,

193 although fungicide did not reduce visible damage, fungicide appears to have alleviated the

194 negative impacts of fungal disease on seedling performance. Contrary to expectation, light and

195 nitrogen did not interact with fungicide to influence seedling height (Nitrogen $\times$ Fungicide $\times$

196 Light: $\mathrm{P}=0.72$; Table S4).

197

198 DiscuSSION

199 In this study, light, nitrogen, and pathogens additively and interactively influenced

200 seedling performance. Contrary to our expectation, nitrogen and light availability interacted to

201 alter foliar fungal damage: damage increased with increasing nitrogen availability, but only in

202 low light. This suggests that increased nitrogen availability under low light makes plants more

203 susceptible to enemies (Dordas 2009, Zhou et al. 2015, Ballaré and Pierik 2017). Although foliar

204 damage was lower under high light, seedling height showed a different pattern: pathogens

205 impacted seedling height more strongly under high light than low light. This is contrary to other

206 studies showing either greater impacts of pathogens and herbivores in low light or no difference

207 in impacts between light environments (e.g., Augspurger 1983, Myers and Kitajima 2007, 
208 Bayandala et al. 2017). Together, these results demonstrate the importance of light and nitrogen

209 for modulating pathogen impacts on seedling performance.

210 Nitrogen and light availability interacted to influence pathogen damage in this study.

211 Specifically, pathogen damage increased with nitrogen availability in the shade, but not in the

212 sun. Because there was not a strong main effect of light, it is unlikely that differences in

213 pathogen inoculum between high and low light environments were entirely responsible for this.

214 Instead, low light may have reduced the ability of seedlings to synthesize defense compounds,

215 either because they lacked the carbon to do so or because the jasmonic and salicylic acid

216 pathways were down-regulated (Stamp 2003, de Wit et al. 2013, Zhou et al. 2015, Ballaré and

217 Pierik 2017, Huang et al. 2020). Either of these mechanisms would reduce the ability of

218 seedlings to resist pathogens, leaving their nitrogen-rich leaves more susceptible to pathogen

219 infection. Together, these possible explanations for the interactive effect of light and nitrogen on

220 pathogen damage have important implications for succession (Griffin et al. 2016, Griffin et al.

221 2017): high nitrogen supply may reinforce the dominance of shade-intolerant species in early

222 stages of succession (i.e., high-light environments) by contributing to growth without increasing

223 damage, but may hinder performance of shade-intolerant species in later successional stages by

224 increasing damage without increasing growth (Reinhart et al. 2010).

225 Nitrogen and light availability also interacted to influence seedling height, a key proxy

226 for seedling performance. Here, seedling height increased with nitrogen availability in high light,

227 but not in low light. This indicates that light was more limiting than nitrogen to growth in the

228 forest understory, but that nitrogen was more limiting than light in the old field. Despite this,

229 nitrogen and light did not simultaneously interact with fungicide application to influence

230 seedling height. Instead, spraying increased seedling height only in high light, which was 
231 contrary to our prediction that pathogen impacts on seedling performance would be larger under

232 low light (Augspurger 1983, Stamp 2003, Myers and Kitajima 2007). This indicates that fungal

233 pathogens were negatively impacting seedling performance in high light, even without visible

234 differences in fungal damage. Additionally, fungal pathogens may not have impacted seedling

235 height in low light because seedling growth was severely light limited regardless of damage.

236 Although this study demonstrates important impacts of light, nutrients, and pathogens on

237 L. styraciflua performance, there are several limitations. First, this study was short. While this

238 short duration highlights a critical life stage — survival and growth of establishing tree seedlings

239 (De Steven 1991, Fridley and Wright 2018) — we cannot account for differences in overwinter

240 survival or impacts of light, nutrients, and pathogens beyond this window. Moreover, we cannot

241 account for differences in shade tolerance across life stages (Valladares and Niinemets 2008,

242 Falster et al. 2018). Second, by growing seedlings alone in pots, we eliminated interspecific

243 competition and may have reduced rain splash dispersal of pathogens. Reduced competition may

244 have been more important in herbaceous-dominated old fields (Flory and Clay 2010, Fridley and

245 Wright 2012) than in the more sparsely vegetated forest understory. Thus, growing seedlings in

246 pots versus directly in the ground may have had a larger impact on plant growth in the

247 herbaceous-dominated old field than in the forest understory. Third, we did not compare $L$.

248 styraciflua to any other shade-intolerant or shade-tolerant species (e.g., Chou et al. 2018).

249 These results suggest that pathogens, nitrogen, and light can be important drivers of

250 succession from old fields to forests (Wright and Fridley 2010, Fridley and Wright 2012,

251 Meiners et al. 2015). Under high light, foliar disease reduced the performance of L. styraciflua.

252 This high pathogen impact may ultimately slow the growth and spread of L. styraciflua in old

253 fields, potentially slowing the conversion of herbaceous-dominated old fields to early- 
254 successional forests (Gill and Marks 1991). In closed-canopy forests, pathogens may also be

255 important determinants of species occurrence patterns (LaManna et al. 2017). For instance,

256 seedlings of shade-intolerant species, like L. styraciflua, do not aggregate as often in forest

257 understories as shade-tolerant species, indicating conspecific negative density dependence (Clark

258 et al. 2004), which may result from foliar (Hersh et al. 2012) or belowground disease. This may

259 prevent shade-intolerant species from maintaining large enough seedling and sapling populations

260 to exploit infrequent tree falls and could result in their exclusion from forest understories

261 (O’Hanlon-Manners and Kotanen 2004, Wulantuya et al. 2020). Moreover, pathogen impacts on

262 shade-intolerant species can increase in shaded habitats, potentially increasing niche

263 differentiation between shade-tolerant and -intolerant species (McCarthy-Neumann and Kobe

264 2008). As in other studies, pathogens in this study were important in low light, where foliar

265 disease increased with increasing nitrogen availability. But increased disease had a limited

266 impact on seedling performance. Instead, light limitation was too severe, even when pathogen

267 pressure and nitrogen limitation were alleviated, to allow rapid seedling growth.

\section{CONCLUSIONS}

269 In conclusion, we found that nitrogen and light interact to impact fungal damage, with the

270 highest levels of damage at high nitrogen and low light. Despite this, spraying fungicide

271 impacted seedling height more under high light than low light, indicating that pathogen pressure

272 was higher when light was abundant and that fungal pathogens exerted negative impacts on

273 seedling performance beyond what was visible on leaves. Overall, though, light limitation had

274 the largest influence on seedling performance, overwhelming both nitrogen limitation and

275 pathogen pressure (Ward 2020). Given this, it appears that the shade-intolerant species $L$.

276 styraciflua can be excluded from later-successional habitats solely by reducing light 
277 availability— high pathogen pressure and nitrogen limitation may further promote this, but are

278 not required.

279

\section{ACKNOWLEDGEMENTS}

281 We thank A. J. Brown, F. Halliday, C. Mitchell, K. O’Keeffe, A. Simha, J. Umbanhowar, and M.

282 Welsh for discussion on previous versions of this manuscript. Thanks to F. Halliday and C.

283 Mitchell for suggestions on the design of the experiment, and J. Umbanhowar for statistical

284 advice. A. Hurlbert and J. Coyle lent us experimental supplies. J. Garzoni and T. Hodges

285 provided help and expertise for the greenhouse experiment. P. Wilfahrt helped with experiment

286 maintenance.

287

288

\section{FUNDING STATEMENT}

289 This study was funded by a National Science Foundation Doctoral Dissertation Improvement 290 Grant to RWH (NSF-DEB-1311289). UNC's Summer Undergraduate Research Fellowship 291 provided summer funding to ANB.

292

293

REFERENCES

294 Addington, R. N., B. O. Knapp, G. G. Sorrell, M. L. Elmore, G. G. Wang, and J. L. Walker. 295 2015. Factors affecting broadleaf woody vegetation in upland pine forests managed for longleaf pine restoration. Forest Ecology and Management 354:130-138.

297 Agrawal, A. A. 2020. A scale-dependent framework for trade-offs, syndromes, and 298 specialization in organismal biology. Ecology 101:e02924. 
299 Augspurger, C. K. 1983. Seed dispersal of the tropical tree, Platypodium elegans, and the escape 300 of its seedlings from fungal pathogens. Journal of Ecology 71:759-771.

301 Augspurger, C. K. 1984a. Light requirements of neotropical tree seedlings: a comparative study 302 of growth and survival. Journal of Ecology 72:777-795.

Augspurger, C. K. 1984b. Seedling survival of tropical tree species: interactions of dispersal distance, light-gaps, and pathogens. Ecology 65:1705-1712.

Ballaré, C. L., and R. Pierik. 2017. The shade-avoidance syndrome: multiple signals and ecological consequences. Plant, Cell \& Environment 40:2530-2543.

Bayandala, K. Masaka, and K. Seiwa. 2017. Leaf diseases drive the Janzen-Connell mechanism

Bever, J. D., S. A. Mangan, and H. M. Alexander. 2015. Maintenance of plant species diversity regardless of light conditions: a 3-year field study. Oecologia 183:191-199.

Borer, E. T., W. S. Harpole, P. B. Adler, E. M. Lind, J. L. Orrock, E. W. Seabloom, and M. D. Smith. 2014. Finding generality in ecology: a model for globally distributed experiments. Methods in Ecology and Evolution 5:65-73.

Brown, A. J., C. J. Payne, P. S. White, and R. K. Peet. 2020. Shade tolerance and mycorrhizal type may influence sapling susceptibility to conspecific negative density dependence. Journal of Ecology 108:325-336.

Bruns, E. L., J. Antonovics, and M. Hood. 2019. Is there a disease-free halo at species range limits? The codistribution of anther-smut disease and its host species. Journal of Ecology 107:1-11. 
320 Cappelli, S. L., N. A. Pichon, A. Kempel, and E. Allan. 2020. Sick plants in grassland

321 communities: a growth-defense trade-off is the main driver of fungal pathogen

$322 \quad$ abundance. Ecology Letters 23:1349-1359.

323 Chou, C. B., L. O. Hedin, and S. W. Pacala. 2018. Functional groups, species and light interact 324 with nutrient limitation during tropical rainforest sapling bottleneck. Journal of Ecology 106:157-167.

Clark, J. S., S. LaDeau, and I. Ibanez. 2004. Fecundity of trees and the colonization-competition hypothesis. Ecological Monographs 74:415-442.

328 Coley, P. D., J. P. Bryant, and F. S. Chapin. 1985. Resource availability and plant antiherbivore defense. Science 230:895-899.

330 Comita, L. S., S. A. Queenborough, S. J. Murphy, J. L. Eck, K. Xu, M. Krishnadas, N. Beckman, 331 and Y. Zhu. 2014. Testing predictions of the Janzen-Connell hypothesis: a meta-analysis of experimental evidence for distance- and density-dependent seed and seedling survival.

334 Cottingham, K. L., J. T. Lennon, and B. L. Brown. 2005. Knowing when to draw the line: designing more informative ecological experiments. Frontiers in Ecology and the Environment 3:145-152.

De Steven, D. 1991. Experiments on mechanisms of tree establishment in old-field succession: seedling survival and growth. Ecology 72:1076-1088. Voesenek, and R. Pierik. 2013. Perception of low red:far-red ratio compromises both salicylic acid- and jasmonic acid-dependent pathogen defences in Arabidopsis. The Plant Journal 75:90-103. 
343 Dordas, C. 2009. Role of nutrients in controlling plant diseases in sustainable agriculture: a

344 review. Pages 443-460 in E. Lichtfouse, M. Navarrete, P. Debaeke, S. Véronique, and C.

345 Alberola, editors. Sustainable Agriculture. Springer Netherlands, Dordrecht.

346 Ekstrøm, C. 2016. MESS: Miscellaneous Esoteric Statistical Scripts. R package version 0.4-3.

347 http://CRAN.R-project.org/package=MESS.

348 Falster, D. S., R. A. Duursma, and R. G. FitzJohn. 2018. How functional traits influence plant growth and shade tolerance across the life cycle. Proceedings of the National Academy of Sciences 115:E6789-E6798.

351 Fay, P. A., et al. 2015. Grassland productivity limited by multiple nutrients. Nature Plants 1:15080.

353 Fine, P. V. A., I. Mesones, and P. D. Coley. 2004. Herbivores promote habitat specialization by 354 trees in Amazonian forests. Science 305:663-665.

355 Flory, S. L., and K. Clay. 2010. Non-native grass invasion suppresses forest succession.

$356 \quad$ Oecologia 164:1029-1038.

357 Fridley, J. D., and J. P. Wright. 2012. Drivers of secondary succession rates across temperate 358 latitudes of the Eastern USA: climate, soils, and species pools. Oecologia 168:1069-1077. 359 Fridley, J. D., and J. P. Wright. 2018. Temperature accelerates the rate fields become forests. $360 \quad$ Proceedings of the National Academy of Sciences 115:4702-4706.

361 Gill, D. S., and P. L. Marks. 1991. Tree and shrub seedling colonization of old fields in central New York. Ecological Monographs 61:183-205.

363 Griffin, E. A., M. B. Traw, P. J. Morin, J. N. Pruitt, S. J. Wright, and W. P. Carson. 2016. Foliar bacteria and soil fertility mediate seedling performance: a new and cryptic dimension of niche differentiation. Ecology 97:2998-3008. 
366 Griffin, E. A., S. J. Wright, P. J. Morin, and W. P. Carson. 2017. Pervasive interactions between

367 foliar microbes and soil nutrients mediate leaf production and herbivore damage in a 368 tropical forest. New Phytologist 216:99-112.

369 Hahn, P. G., and J. L. Maron. 2016. A framework for predicting intraspecific variation in plant 370 defense. Trends in Ecology \& Evolution 31:646-656.

371 Halliday, F. W., J. Umbanhowar, and C. E. Mitchell. 2017. Interactions among symbionts operate across scales to influence parasite epidemics. Ecology Letters 20:1285-1294.

373

374

375

376

377

378

379

380

381

382

383

384

385

386

387

388

Hanssen, K. H., J. Asplund, N. Clarke, R. Selmer, and L. Nybakken. 2020. Fertilization of Norway spruce forest with wood ash and nitrogen affected both tree growth and composition of chemical defence. Forestry: An International Journal of Forest Research 93:589-600.

Hatcher, P. E., P. G. Ayres, and N. D. Paul. 1995. The effect of natural and simulated insect herbivory, and leaf age, on the process of infection of Rumex crispus L. and $R$. obtusifolius L. by Uromyces rumicis (Schum.) Wint. New Phytologist 130:239-249.

Heckman, R. W., F. W. Halliday, and C. E. Mitchell. 2019. A growth-defense trade-off is general across native and exotic grasses. Oecologia 191:609-620.

Heckman, R. W., F. W. Halliday, P. A. Wilfahrt, and C. E. Mitchell. 2017. Effects of native diversity, soil nutrients, and natural enemies on exotic invasion in experimental plant communities. Ecology 98:1409-1418.

Heckman, R. W., J. P. Wright, and C. E. Mitchell. 2016. Joint effects of nutrient addition and enemy exclusion on exotic plant success. Ecology 97:3337-3345.

Hersh, M. H., R. Vilgalys, and J. S. Clark. 2012. Evaluating the impacts of multiple generalist fungal pathogens on temperate tree seedling survival. Ecology 93:511-520. 
389 Huang, J., A. Rücker, A. Schmidt, G. Gleixner, J. Gershenzon, S. Trumbore, and H. Hartmann. 390 2020. Production of constitutive and induced secondary metabolites is coordinated with 391 growth and storage in Norway spruce saplings. Tree Physiology 40:928-942.

392 James, C. 1971. A manual of assessment keys for plant diseases. American Phytopathological 393 Society, St. Paul, Minnesota, USA.

394 Jia, S., X. Wang, Z. Yuan, F. Lin, J. Ye, G. Lin, Z. Hao, and R. Bagchi. 2020. Tree species traits 395 affect which natural enemies drive the Janzen-Connell effect in a temperate forest. Nature 396 Communications 11:286.

397 Kitajima, K., and L. Poorter. 2010. Tissue-level leaf toughness, but not lamina thickness, 398 predicts sapling leaf lifespan and shade tolerance of tropical tree species. New Phytologist 186:708-721.

Kope, H. H., and D. Trotter. 1998. Evaluation of mancozeb and propiconazole to control Keithia 402 leaf blight of container-grown western red cedar. Forestry Chronicle 74:583-587.

Krishnadas, M., and L. S. Comita. 2018. Influence of soil pathogens on early regeneration success of tropical trees varies between forest edge and interior. Oecologia 186:259-268.

LaManna, J. A., et al. 2017. Plant diversity increases with the strength of negative density dependence at the global scale. Science 356:1389-1392.

Lenth, R. 2018. emmeans: Estimated marginal means, aka least-squares means. https://CRAN.Rproject.org/package $=$ emmeans.

Liu, X., S. Lyu, D. Sun, C. J. A. Bradshaw, and S. Zhou. 2017. Species decline under nitrogen 409 fertilization increases community-level competence of fungal diseases. Proceedings of the Royal Society B: Biological Sciences 284. 
411 Lorenz, E. J., and J. T. Cothren. 1989. Photosynthesis and yield of wheat (Triticum aestivum)

412 treated with fungicides in a disease-free environment Plant Disease 73:25-27.

413 Maron, J. L., M. Marler, J. N. Klironomos, and C. C. Cleveland. 2011. Soil fungal pathogens and 414 the relationship between plant diversity and productivity. Ecology Letters 14:36-41.

415 McCarthy-Neumann, S., and R. K. Kobe. 2008. Tolerance of soil pathogens co-varies with shade 416 tolerance across species of tropical tree seedlings. Ecology 89:1883-1892.

417 McElrone, A. J., J. G. Hamilton, A. J. Krafnick, M. Aldea, R. G. Knepp, and E. H. DeLucia. 2010. Combined effects of elevated $\mathrm{CO}_{2}$ and natural climatic variation on leaf spot

Meiners, S. J., M. W. Cadotte, J. D. Fridley, S. T. A. Pickett, and L. R. Walker. 2015. Is successional research nearing its climax? New approaches for understanding dynamic communities. Functional Ecology 29:154-164.

Mitchell, C. E. 2003. Trophic control of grassland production and biomass by pathogens. Ecology Letters 6:147-155.

Mitchell, C. E., P. B. Reich, D. Tilman, and J. V. Groth. 2003. Effects of elevated $\mathrm{CO}_{2}$, nitrogen deposition, and decreased species diversity on foliar fungal plant disease. Global Change Biology 9:438-451.

Mitchell, C. E., D. Tilman, and J. V. Groth. 2002. Effects of grassland plant species diversity, abundance, and composition on foliar fungal disease. Ecology 83:1713-1726.

Mordecai, E. A. 2011. Pathogen impacts on plant communities: unifying theory, concepts, and 431 empirical work. Ecological Monographs 81:429-441.

432 Myers, J. A., and K. Kitajima. 2007. Carbohydrate storage enhances seedling shade and stress 433 tolerance in a neotropical forest. Journal of Ecology 95:383-395. 
434 O'Hanlon-Manners, D. L., and P. M. Kotanen. 2004. Evidence that fungal pathogens inhibit

435 recruitment of a shade-intolerant tree, white birch (Betula papyrifera), in understory

436 habitats. Oecologia 140:650-653.

437 Oosting, H. J. 1942. An ecological analysis of the plant communities of Piedmont, North

438 Carolina. American Midland Naturalist 28:1-126.

439 Parker, I. M., and G. S. Gilbert. 2007. When there is no escape: the effects of natural enemies on 440 native, invasive, and noninvasive plants. Ecology 88:1210-1224.

441 Pasquini, S. C., S. J. Wright, and L. S. Santiago. 2015. Lianas always outperform tree seedlings

442 regardless of soil nutrients: results from a long - term fertilization experiment. Ecology

$443 \quad 96: 1866-1876$.

444 Pinheiro, J., D. Bates, S. DebRoy, and D. Sarkar. 2016. nlme: linear and nonlinear mixed effects 445 models. R package version 3.1-127.

446 Reinhart, K. O., T. Tytgat, W. H. Van der Putten, and K. Clay. 2010. Virulence of soil-borne 447 pathogens and invasion by Prunus serotina. New Phytologist 186:484-495.

448 Spear, E. R., P. D. Coley, and T. A. Kursar. 2015. Do pathogens limit the distributions of tropical 449 trees across a rainfall gradient? Journal of Ecology 103:165-174.

450 Stamp, N. 2003. Out of the quagmire of plant defense hypotheses. Quarterly Review of Biology 451 78:23-55.

452 Stevens, C. J., et al. 2015. Anthropogenic nitrogen deposition predicts local grassland primary 453 production worldwide. Ecology 96:1459-1465.

454 Thaler, J. S., P. T. Humphrey, and N. K. Whiteman. 2012. Evolution of jasmonate and salicylate 455 signal crosstalk. Trends in Plant Science 17:260-270. 
456 Uricchio, L. H., S. C. Daws, E. R. Spear, and E. A. Mordecai. 2019. Priority effects and

457 nonhierarchical competition shape species composition in a complex grassland

458 community. The American Naturalist 193:213-226.

459 Valladares, F., and Ü. Niinemets. 2008. Shade tolerance, a key plant feature of complex nature 460 and consequences. Annual Review of Ecology, Evolution, and Systematics 39:237.

461 Veresoglou, S. D., E. K. Barto, G. Menexes, and M. C. Rillig. 2013. Fertilization affects severity 462 of disease caused by fungal plant pathogens. Plant Pathology 62:961-969.

463 Walters, M. B., and P. B. Reich. 1999. Low-light carbon balance and shade tolerance in the 464 seedlings of woody plants: do winter deciduous and broad-leaved evergreen species

465 differ? New Phytologist 143:143-154.

466 Ward, D. 2020. Shade is the most important factor limiting growth of a woody range expander. Plos One 15:e0242003.

468 Welsh, M. E., J. P. Cronin, and C. E. Mitchell. 2016. The role of habitat filtering in the leaf 469 economics spectrum and plant susceptibility to pathogen infection. Journal of Ecology 104:1768-1777.

471 Wright, J. P., and J. D. Fridley. 2010. Biogeographic synthesis of secondary succession rates in 472 eastern North America. Journal of Biogeography 37:1584-1596.

473 Wulantuya, K. Masaka, Bayandala, Y. Fukasawa, K. Matsukura, and K. Seiwa. 2020. Gap 474 creation alters the mode of conspecific distance-dependent seedling establishment via 475 changes in the relative influence of pathogens and mycorrhizae. Oecologia 192:449-462.

476 Zhou, S., Y.-R. Lou, V. Tzin, and G. Jander. 2015. Alteration of plant primary metabolism in 477 response to insect herbivory. Plant physiology 169:1488-1498. 
478 Zuur, A., E. N. Ieno, N. Walker, A. A. Saveliev, and G. M. Smith. 2009. Mixed effects models

479 and extensions in ecology with R. Springer Science \& Business Media, New York.

480

481 FigurE LEGENDS

482 Fig. 1 a) Effects of fungicide spraying on mean foliar fungal damage ( $N=128$ seedlings), b)

483 effects of nitrogen and light availability on mean foliar fungal damage for seedlings not sprayed

484 with fungicide $(\mathrm{N}=64$ seedlings: 20 in low light, 44 in high light); dashed lines represent plants

485 growing in low light and solid lines represent plants growing in high light. Means and 95\%

486 confidence intervals were calculated using linear mixed models and back transformed from a

487 cubed root transformation.

488

489 Fig. 2 Effects of nitrogen and light availability, and fungicide spraying on seedling height $(\mathrm{N}=$ 490128 seedlings: 40 in low light, 88 in high light). Dashed lines represent plants growing in low

491 light and solid lines represent plants growing in high light. Means and 95\% confidence intervals 492 were calculated using linear mixed models. 


\section{Figure 1}

Effects of nitrogen and light availability on mean foliar fungal damage

a) Effects of fungicide spraying on mean foliar fungal damage ( $N=128$ seedlings), b) effects of nitrogen and light availability on mean foliar fungal damage for seedlings not sprayed with fungicide ( $N=64$ seedlings: 20 in low light, 44 in high light); dashed lines represent plants growing in low light and solid lines represent plants growing in high light. Means and 95\% confidence intervals were calculated using linear mixed models and back transformed from a cubed root transformation.
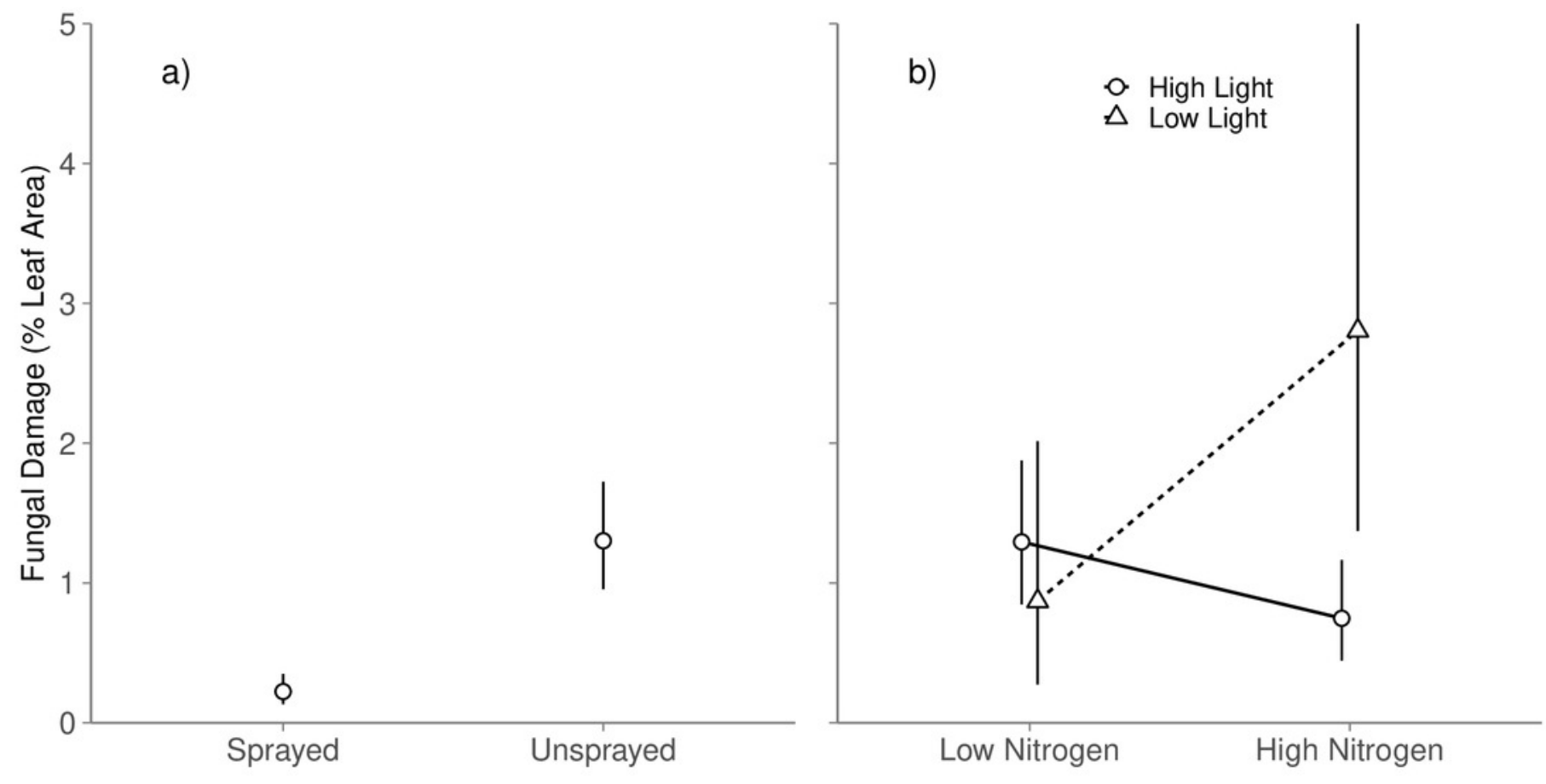
Figure 2

Effects of nitrogen and light availability, and damage treatment on height accumulation in the field

Effects of nitrogen and light availability, and fungicide spraying on seedling height $(\mathrm{N}=128$ seedlings: 40 in low light, 88 in high light). Dashed lines represent plants growing in low light and solid lines represent plants growing in high light. Means and 95\% confidence intervals were calculated using linear mixed models.

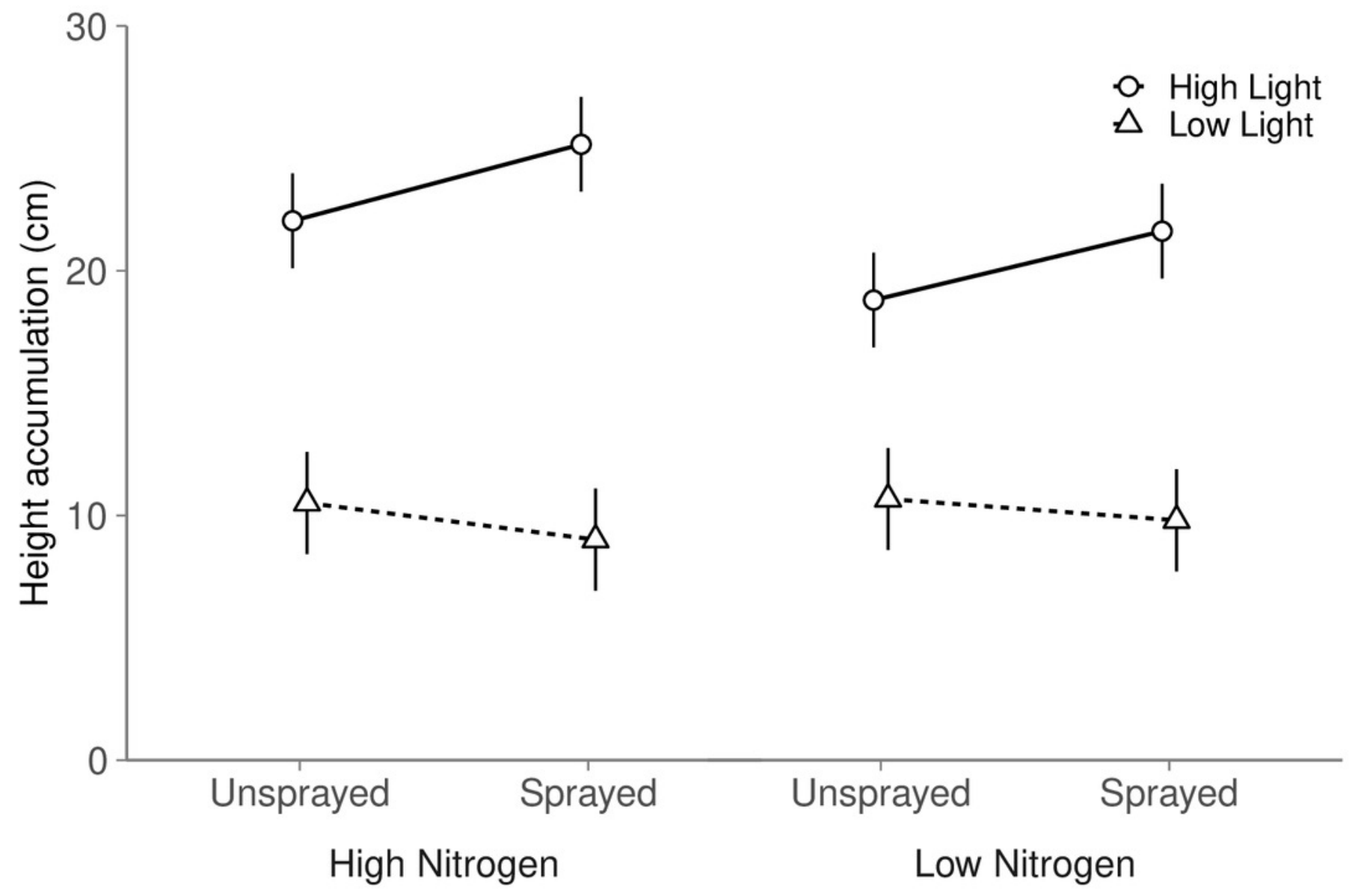

